\title{
Effects of raloxifene on gonadotrophins, sex hormones, bone turnover and lipids in healthy elderly men
}

\author{
Erik J J Duschek, Louis J Gooren and Coen Netelenbos \\ Department of Endocrinology, VU University Medical Centre, The Netherlands \\ (Correspondence should be addressed to Erik J J Duschek, Department of Endocrinology, VU University Medical Centre, PO Box 7057 , \\ 1007 MB Amsterdam, The Netherlands; Email: e.duschek@vumc.nl)
}

\begin{abstract}
Objective: To explore effects on serum lipids, pituitary-gonadal axis, prostate and bone turnover of the administration of the mixed oestrogen agonist/antagonist raloxifene in healthy elderly men. Participants: Thirty healthy men aged 60-70 years randomly received raloxifene $120 \mathrm{mg} /$ day $(n=15)$ or placebo $(n=15)$ for 3 months.

Measurements: In this double-blind, placebo-controlled study, serum gonadotrophins, sex hormones, prostate specific antigen (PSA), a marker of bone turnover, urinary hydroxyproline (OHPro) and cholesterol were measured at baseline and after 3 months.

Results: Raloxifene significantly increased serum concentrations of LH and FSH (by 29\% and 21\%), total testosterone $(20 \%)$, free testosterone $(16 \%)$ and bioavailable testosterone (not bound to sex hormone-binding globulin (SHBG; 20\%). In parallel with testosterone, $17 \beta$-oestradiol also increased by $21 \%$. SHBG increased by $7 \%$. Total cholesterol (TChol) decreased significantly, from 5.7 to $5.5 \mathrm{mmol} / \mathrm{l}$ $(P=0.03)$. Low-density lipoprotein cholesterol (LDL-c) and high-density lipoprotein cholesterol (HDL-c) showed a trend to decrease. Overall, there was no change in urinary OHPro/creatinine ratio as a marker for bone resorption. However, the raloxifene-induced increases in both serum testosterone and $17 \beta$-oestradiol were significantly related to a lower OHPro/creatinine ratio. Total PSA increased by $17 \%$ without significant changes in free PSA or free/total PSA ratio. Participants reported no side effects and raloxifene was well tolerated.

Conclusion: In healthy elderly man, raloxifene $120 \mathrm{mg}$ /day for 3 months increased LH, FSH and sex steroid hormones. Potentially beneficial effects were the small but significant decrease in TChol and the trend towards a decrease in LDL-c. Negative effects were the trend towards a decrease in HDL-c and the significant increase in serum PSA. A decrease in markers of bone resorption during raloxifene treatment was found only in men with relatively high increases in serum testosterone and $17 \beta$-oestradiol. Overall, there were no clear beneficial effects of administration of raloxifene to ageing men in this preliminary investigation.
\end{abstract}

European Journal of Endocrinology 150 539-546

\section{Introduction}

The favourable effects of raloxifene on bone mineral density and on surrogate markers of cardiovascular disease in postmenopausal women are now well documented $(1-4)$. Raloxifene is a non-steroidal partial oestrogen agonist (also called a selective oestrogen receptor modulator or SERM) with mixed agonist and antagonist properties that vary in different tissues. For a number of reasons, its use might also have potential benefits in ageing men. Androgen concentrations decline over a man's lifetime (5), and in about $20 \%$ of men older than 60 years the serum concentrations of testosterone are in the hypogonadal range (6). Administration of a SERM might increase gonadotrophins and, subsequently, testosterone concentrations; furthermore, although traditionally perceived as 'female hormones', oestrogens appear to have significant physiological effects in the male biological system $(7,8)$. Oestrogens exert beneficial effects on skeletal growth and bone maturation. In old age, they are better predictors of bone fractures than androgens (9). The effects of oestrogen on the brain are increasingly becoming clear: they affect cognitive function, co-ordination of movement, pain and affective state, and may be protective against Alzheimer's disease (10). The effects of oestrogen on the cardiovascular system in males include those on lipid profiles, fat distribution, endocrine/paracrine factors produced by the vascular wall (such as endothelins, nitric oxide), blood platelets, inflammatory factors and coagulation $(8,11-14)$. Recent evidence also points to a role of oestrogens in male sexual functioning, particularly on libido (15). There may, however, be potentially adverse effects of oestrogens on the prostate. Prostate disease occurs typically in old age, when there is usually a shift in the oestrogen/androgen ratio 
in favour of oestrogens. Oestrogens have been reported to induce androgen receptors in the stroma of the prostate, thus contributing to the development of benign prostate hyperplasia $(14,16)$. The relationship between circulating oestrogen concentrations and prostate cancer is unclear.

Tamoxifen, another partial oestrogen agonist and antagonist, has been widely used for the prevention and treatment of breast carcinoma in pre- and postmenopausal women $(17,18)$. It has long been noted to reduce the risk of fatal and non-fatal myocardial infarction in postmenopausal women $(19,20)$. Studies with tamoxifen have been performed in men. Treatment with tamoxifen for 56 days in men with and without advanced arteriosclerosis had beneficial effects on markers of cardiovascular risk (21). In these men, tamoxifen decreased serum total cholesterol (TChol), triglycerides, lipoprotein(a) and fibrinogen, and it also substantially decreased endothelium-dependent flow-mediated vasodilatation. A negative effect of tamoxifen was a decrease in high-density lipoprotein cholesterol (HDL-c) (21). Treatment with raloxifene $60 \mathrm{mg} /$ day in hypercholesterolaemic men for 1 month significantly decreased TChol, but without any significant effect on low-density lipoprotein cholesterol (LDL-c), HDL-c, triglycerides and lipoprotein(a) (22). In postmenopausal women, raloxifene used for prevention and treatment of postmenopausal osteoporosis $(1,23)$, exerts beneficial, oestrogen-agonistic effects on cardiovascular risk factors $(3,24-26)$. Unlike tamoxifen, raloxifene does not stimulate endometrial tissue in postmenopausal women (2).

Ideally, in men these partial oestrogen agonists/antagonists would increase the production of testicular androgen by its antioestrogenic effects on the hypothalamo-pituitary unit and, at the same time, by its oestrogenic actions, have beneficial effects on bones, cardiovascular risk factors and psychosexual functioning. There is only limited information on the effects of the administration of raloxifene to men in whom circulating concentrations of $17 \beta$-oestradiol are higher than in postmenopausal women (9). In the present study in elderly males, we explored the effects of raloxifene on serum lipids, pituitary-gonadal axis, prostate and bone turnover. Raloxifene was given in a dose of $120 \mathrm{mg} /$ day, double the dose used in a previous study (27). Naturally, a new drug with both oestrogenic and antioestrogenic effects may have potentially hazardous effects on male (patho)physiology such as the prostate. Therefore, the duration of the study was limited, and only ageing men who had completed their procreation were admitted to the study. The administration of an oestrogen receptor antagonist to men is not novel: the similarly dually active compound, tamoxifen, has been administered to many thousands of men as a fertility-promoting drug, and no side effects have been reported in the literature. In addition, raloxifene treatment in men for 6 months was found to have no significant side effects (27).

\section{Participants and methods}

\section{Participants}

Thirty healthy men aged between 60 and 70 years were included in this study. They were recruited through newspaper advertisements and from posters distributed in the VU University Medical Centre. The men underwent a screening questionnaire by phone. Exclusion criteria were: history of stroke, Parkinson's disease or psychiatric disorder; thromboembolic events in the participant or his first-degree relatives; chronic liver or kidney disease, or both; endocrine diseases including bone diseases; cardiovascular or prostatic disease. Other contraindications were the use of medication for prostate, cardiovascular system and bone metabolism. Medication influencing cerebral function or the hormones of the pituitary-gonadal and adrenal axis was a ground for exclusion, as were complaints with respect to libido, psychosexual disorders, and the intention to father children. Hypertension was not an exclusion criterion. The men were randomly assigned to receive raloxifene hydrochloride $120 \mathrm{mg} /$ day $(n=15)$ or placebo $(n=15)$. The medication was identically packaged, so that both the study men and the researchers were blinded to the medication given. The study was conducted on an outpatient basis according to the principles of the Declaration of Helsinki and was approved by the medical ethics review board of the VU University Medical Centre of Amsterdam. Informed consent was obtained from all volunteers after oral and written information had been given.

\section{General procedures}

At baseline, smoking status (yes/no), weight and blood pressure were recorded. After the participant had completed a medical history questionnaire, a physical examination including digital rectal prostate examination was performed. Blood samples at baseline and after 3 months of treatment were collected between $0800 \mathrm{~h}$ and $1130 \mathrm{~h}$, after an overnight fast. The samples were stored at $-70^{\circ} \mathrm{C}$ until required for analysis. In addition, participants collected 2-h fasting urine samples for measurement of bone resorption, for which urine hydroxyproline (OHPro)/creatinine ratio was used as a marker (28).

\section{Laboratory variables}

At baseline and after 3 months, serum calcium, phosphate, alkaline phosphatase and albumin were measured using standard laboratory methods. Serum TChol and triglyceride concentrations were measured by colorimetry and HDL-c by a direct method (Roche Diagnostics). LDL-c was calculated by the Friedewald formula. Urine OHPro was measured by high performance liquid chromatography as described previously 
(29). Urine creatinine was measured by the Jaffé method (Roche Diagnostics). The urine OHPro/creatinine ratio was calculated $(\times 1000)$. Serum $17 \beta$-oestradiol was measured by RIA (Double Antibody, Diasorin Biomedica, Saluggia, Italy), with an intra-assay coefficient of variation (CV) of $14 \%$. Serum luteinizing hormone (LH) and follicle-stimulating hormone (FSH) were measured by an immunometric assay (Fluorescense, Delfia, Wallac, Turku, Finland); the intra-assay CVs were both 3\%. Sex hormone-binding globulin (SHBG) was measured by immunoradiometric assay (Orion Diagnostica, Espoo, Finland) with an intra-assay CV of $4 \%$. Serum total testosterone was measured by RIA (Coat-A-Count, Diagnostic Products Corporation, Los Angeles, California, USA), intra-assay CV 6\%. Free and bioavailable (not bound to SHBG) testosterone were calculated by making a syntax for SPSS computer program using the free testosterone calculator on www.issam.ch (The International Society for the Study of the Aging Male). For this calculation, total testosterone, albumin and SHBG values are needed. This calculator was developed at the Endocrine Department, University Hospital of Gent, Belgium, on the basis of the findings of an earlier study (30). Serum total and free prostate specific antigen (PSA) were measured using an immunometric assay (Luminescence, Abbott Laboratories Diagnostic Division, Abbott Park, Illinois, USA); the intra-assay CVs were both 5\%. All hormonal and PSA specimens from a single participant were run in the same assay batch.

\section{Statistical analysis}

The SPSS for Windows 9.0 computer program was used for statistical analyses. Values given and changes from baseline are means \pm S.E.M. (unless otherwise stated). Variables with a skewed distribution (oestrogen, total PSA, triglyceride and urinary calcium/creatinine and OHPro/creatinine ratio) are given as the geometric mean with the $95 \%$ confidence interval. Because of the small numbers of participants, non-parametric tests were used. The Mann-Whitney U-test was used to test group differences at baseline and to evaluate differences between treatment group and placebo. For the change within the two treatment groups compared with baseline, the Wilcoxon Signed Rank Test was used. Correlations between baseline characteristics and changes from baseline and treatment effects were calculated using Spearman's rank correlation. $P$ values less than 0.05 were considered statistically significant.

\section{Results}

\section{General characteristics}

At baseline there was no differences in age, weight, smoking status or blood pressure between the treatment groups. In both placebo-treated and raloxifene-treated men, weight increased, but this increase was significantly different from baseline only with raloxifene $(2.5 \mathrm{~kg}$, compared with $1.4 \mathrm{~kg}$ for placebo; $P 0.02$; Table 1). During the 3 months of treatment, there was no significant change in blood pressure in either placebo or raloxifene treatment group.

\section{Gonadotrophins and sex hormones}

Values were not different at baseline in the two treatment groups. One man, receiving placebo, had a hypogonadal value of serum total testosterone $[6.9 \mathrm{nmol} / \mathrm{l}$ (normal value $>8 \mathrm{nmol} / \mathrm{l}$ )], with $\mathrm{LH} 2.8 \mathrm{U} / \mathrm{l}$ and $\mathrm{FSH} 3.9 \mathrm{U} / \mathrm{l}$. In the placebo group, no change in gonadotrophins and sex hormones occurred. In contrast, raloxifene induced significantly greater serum concentrations of $\mathrm{LH}$ (change from 3.7 to $4.5 \mathrm{U} / \mathrm{l} ; \quad P=0.008$ ) and $\mathrm{FSH}$ (change from 6.0 to $7.7 \mathrm{U} / \mathrm{l} ; P=0.001$ ) (Table 1 ). This increase in gonadotrophins, especially that in LH, was accompanied by increases in serum total testosterone (from 17.1 to $20.1 \mathrm{nmol} / \mathrm{l} ; P=0.003$ ) and $17 \beta$-oestradiol (from 74.2 to $87.5 \mathrm{pmol} / \mathrm{l} ; \quad P=0.03$ ). These increases in serum testosterone and $17 \beta$-oestradiol showed no significant relationship with their baseline serum values, in both the group receiving raloxifene and that given placebo.

\section{Lipids}

As shown in Table 1, at baseline significantly greater HDL-c concentrations were found in the raloxifene treatment group than in the placebo group ( $1.63 \mathrm{mmol} / \mathrm{l}$ compared with $1.39 \mathrm{mmol} / \mathrm{l} ; P=0.02$ ). In addition, the baseline concentration of triglyceride was significantly lower in these men $(1.2 \mathrm{mmol} / \mathrm{l} \mathrm{com-}$ pared with $1.7 \mathrm{mmol} / \mathrm{l} ; P=0.016)$. After 3 months of treatment with raloxifene, TChol decreased significantly, from 5.7 to $5.5 \mathrm{mmol} / \mathrm{l}(P=0.03)$. In addition, in the men treated with raloxifene, non-significant trends to lower LDL-c $(-4.5 \%)$ and HDL-c $(-2.3 \%)$ values were observed.

\section{Prostate}

The range of PSA and free PSA concentrations at baseline for all men in the study were $0.4-7.8 \mu \mathrm{g} / \mathrm{l}$ and $0.11-1.38 \mu \mathrm{g} / \mathrm{l}$, respectively. At baseline there was no difference in total and free PSA and the calculated ratio between the groups receiving raloxifene and placebo (Table 1). Treatment with raloxifene significantly increased total PSA, from 1.2 to $1.4 \mu \mathrm{g} / \mathrm{l}(P=0.036$; Table 1). No change was found in the value of free PSA or the free/total PSA ratio. There was no correlation between concentrations or changes in concentrations of both total testosterone and oestrogen and basal PSA concentrations or changes in serum PSA concentrations during treatment with raloxifene. 
Table 1 Baseline characteristics and results after 3 months.

\begin{tabular}{|c|c|c|c|c|c|c|}
\hline & $\begin{array}{c}\text { Placebo baseline } \\
\quad(n=15)\end{array}$ & $\begin{array}{c}3 \text { months } \\
(n=15)\end{array}$ & $P$ & $\begin{array}{l}\text { Raloxifene baseline } \\
\qquad(n=15)\end{array}$ & $\begin{array}{l}3 \text { months } \\
(n=15)\end{array}$ & $P$ \\
\hline Age (years) & $64.1 \pm 0.6$ & & & $63.1 \pm 0.6$ & & \\
\hline Smokers (no.) & 2 & & & 1 & & \\
\hline Weight (kg) & $82.5 \pm 4.2$ & $83.9 \pm 4.2$ & NS & $80.1 \pm 2.2$ & $82.6 \pm 2.2$ & 0.002 \\
\hline LH $(\mathrm{U} / \mathrm{l})$ & $3.9 \pm 0.5$ & $3.8 \pm 0.5$ & NS & $3.7 \pm 0.4$ & $4.5 \pm 0.3$ & 0.008 \\
\hline FSH (U/l) & $5.7 \pm 0.8$ & $6.4 \pm 1.0$ & NS & $6.0 \pm 0.7$ & $7.2 \pm 0.9$ & 0.001 \\
\hline $\mathrm{TT}(\mathrm{nmol} / \mathrm{l})$ & $15.7 \pm 1.0$ & $15.4 \pm 1.1$ & NS & $17.1 \pm 1.3$ & $20.1 \pm 1.4$ & 0.003 \\
\hline $\mathrm{FT}(\mathrm{nmol} / \mathrm{l})$ & $0.31 \pm 0.02$ & $0.28 \pm 0.01$ & NS & $0.33 \pm 0.02$ & $0.37 \pm 0.02$ & 0.005 \\
\hline $\mathrm{BT}(\mathrm{nmol} / \mathrm{l})$ & $6.6 \pm 0.5$ & $6.3 \pm 0.3$ & NS & $7.0 \pm 0.5$ & $8.2 \pm 0.5$ & 0.003 \\
\hline $17 \beta$-Oestradiol $(\mathrm{pmol} / \mathrm{l})$ & 68.8 (61.9 to 78.9$)$ & 67.9 (59.4 to 81.0$)$ & NS & $74.2(64.1$ to 90.4$)$ & 87.5 (75.6 to 106.2$)$ & 0.03 \\
\hline SHBG $(\mathrm{nmol} / \mathrm{l})$ & $39.2 \pm 2.1$ & $41.2 \pm 3.3$ & NS & $41.7 \pm 3.7$ & $44.4 \pm 3.8$ & 0.04 \\
\hline TChol (mmol/l) & $5.7 \pm 0.3$ & $5.8 \pm 0.3$ & NS & $5.7 \pm 0.2$ & $5.5 \pm 0.2$ & 0.03 \\
\hline LDL-c (mmol/l) & $3.5 \pm 0.3$ & $3.6 \pm 0.3$ & NS & $3.6 \pm 0.2$ & $3.4 \pm 0.2$ & NS \\
\hline HDL-c (mmol/li) & $1.39 \pm 0.09$ & $1.47 \pm 0.08$ & NS & $1.63 \pm 0.08$ & $1.60 \pm 0.10$ & NS \\
\hline $\mathrm{TG}(\mathrm{mmol} / \mathrm{l})$ & 1.6 (1.3 to 2.2$)$ & 1.1 (1.0 to 2.0$)$ & NS & $1.1(1.0$ to 1.4$)$ & $1.1(0.9$ to 1.4$)$ & NS \\
\hline $\operatorname{tPSA}(\mu \mathrm{g} / \mathrm{l})$ & $1.3(0.7 ; 3.5)$ & $1.3(0.7$ to 3.8$)$ & NS & $1.2(0.8$ to 2.6$)$ & $1.4(1.0$ to 3.1$)$ & 0.036 \\
\hline fPSA $(\mu \mathrm{g} / \mathrm{l})$ & $0.48 \pm 0.09$ & $0.48 \pm 0.09$ & NS & $0.52 \pm 0.10$ & $0.57 \pm 0.11$ & NS \\
\hline fPSA/tPSA ratio & $0.32 \pm 0.04$ & $0.32 \pm 0.03$ & NS & $0.37 \pm 0.05$ & $0.33 \pm 0.04$ & NS \\
\hline Calcium ( $\mathrm{mmol} / \mathrm{l})$ & $2.29 \pm 0.02$ & $2.30 \pm 0.02$ & NS & $2.31 \pm 0.02$ & $2.28 \pm 0.01$ & 0.02 \\
\hline Urine $\mathrm{Ca} / \mathrm{Cr}$ & $0.25(0.19$ to 0.45$)$ & $0.25(0.16$ to 0.50$)$ & NS & $0.18(0.15$ to 0.28$)$ & $0.23(0.19$ to 0.31$)$ & NS \\
\hline Urine OHPro/Cr & 16.8 (13.8 to 22.0$)$ & $16.2(14.4$ to 19.3$)$ & NS & $15.9(13.5$ to 20.1$)$ & 15.1 (13.0 to 18.6 ) & NS \\
\hline
\end{tabular}

Data are mean \pm S.E.M. or, for non-normally distributed variables, geometric mean with $95 \%$ confidence interval. BT, bioavailable testosterone; Ca, calcium; $\mathrm{Cr}$, creatinine; FSH, follicle-stimulating hormone; FT, free testosterone; HDL-c, LDL-c, high- and low-density lipoprotein cholesterols; LH, luteinizing hormone; OHPro, hydroxyproline; fPSA, tPSA, free and total prostate specific antigens; fPSA/tPSA ratio, free/total PSA; SHBG, sex hormone binding globulin; TChol, total cholesterol; TG, triglycerides; TT, total testosterone. NS, not significant.

\section{Bone turnover}

There were no known cases of osteoporosis or recent bone fractures in the men included in the study. In this study, raloxifene had no effect on serum phosphate, alkaline phosphatase or the fasting urine calcium/creatinine and OHPro/creatinine ratios. Serum calcium decreased from 2.31 to $2.28 \mathrm{mmol} / \mathrm{l}(P=0.02)$ with raloxifene (Table 1). This significant decrease in serum calcium concentrations persisted after correction for serum albumin concentrations. No significant relationship between baseline serum $17 \beta$-oestradiol or testosterone and change in urinary calcium/creatinine or OHPro/creatinine ratio was found. However, during treatment with raloxifene, a clear relationship between increases in serum testosterone or $17 \beta$-oestradiol concentrations and OHPro/creatinine ratio was observed (Fig. 1). The increase in both serum $17 \beta$-oestradiol and total testosterone during treatment with raloxifene was significantly related to a low $\mathrm{OHPro} /$ creatinine ratio $(R=-0.58, P=0.024$, for serum total testosterone and $R=-0.72, P=0.002$, for serum $17 \beta$-oestradiol).

\section{Side effects}

During the 3 months of raloxifene treatment, no serious adverse effects such as thromboembolism occurred. Compliance was good as assessed by tablet counts, and there were no withdrawals from the study. There were no reports of prostatic complaints, erection problems or decreased libido. One man, in the raloxifene treatment group, reported an improvement in urine flow. Another man treated with raloxifene reported breast tenderness without signs of gynaecomastia, but this did not cause him to stop the medication. An increase in muscle cramps of the legs was reported in three men in the placebo group and one man in the raloxifene group.

\section{Discussion}

Raloxifene is a non-steroidal drug with partially agonistic oestrogenic and partially antioestrogenic properties. In postmenopausal women (whose endogenous oestrogen concentrations are very low) its oestrogenic properties are utilized for the prevention and treatment of osteoporosis. Clinical trials with raloxifene in postmenopausal women have also shown beneficial effects on surrogate markers of cardiovascular disease (3, 2426). Because of the antioestrogenic effects, raloxifene seems to reduce the risk of breast cancer $(31,32)$ and does not stimulate endometrial tissue in postmenopausal women $(2,33)$.

In postmenopausal women with low endogenous oestrogens, raloxifene decreases serum FSH without affecting serum LH or serum $17 \beta$-oestradiol, whereas serum SHBG increases. These effects are interpreted as oestrogenic. The effect of raloxifene on serum testosterone in women is unknown $(34,35)$. Raloxifene and another mixed oestrogen agonist/antagonist, tamoxifen, have been studied in men. Serum concentrations of total and bioavailable (not SHBG bound) $17 \beta$-oestradiol are approximately twice as high in men as in postmenopausal women (9): in both young and elderly men, mean serum total $17 \beta$-oestradiol concentrations are in the 


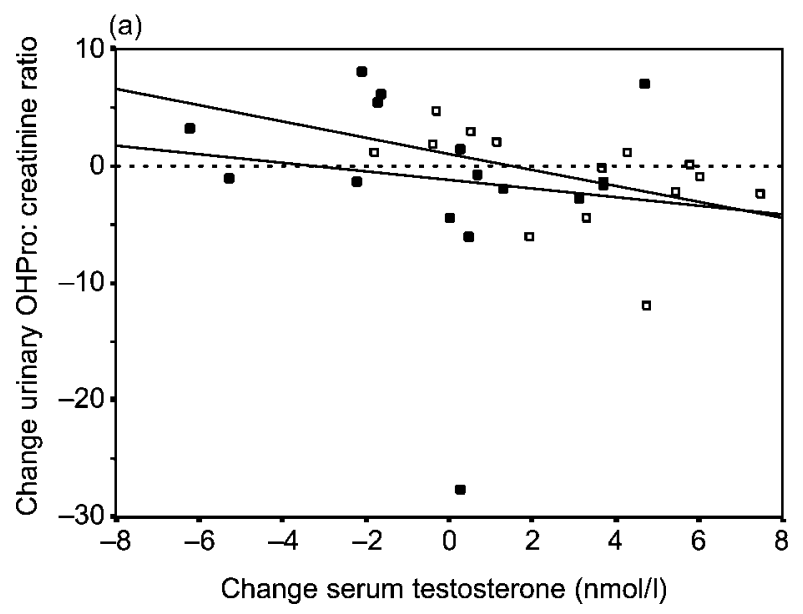

(b)

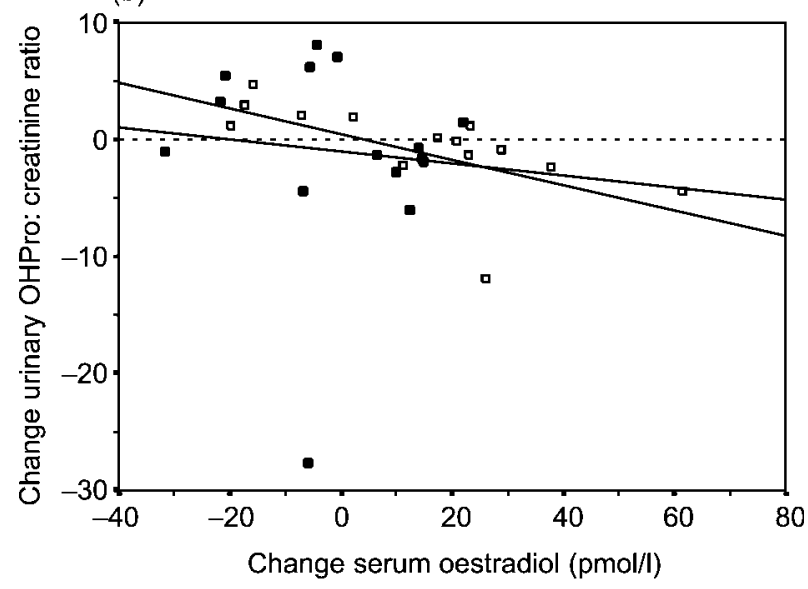

Figure 1 Scatter plots of change in (a) serum total testosterone and (b) serum total $17 \beta$-oestradiol after 3 months, compared with change in urinary hydroxyproline (OHPro)/creatinine ratio, in men treated with raloxifene $(\square)$ or placebo (ם). During treatment with raloxifene, a decrease in urinary OHPro:creatinine ratio was significantly correlated with increases in serum total testosterone $(R=-0.59 ; P=0.024)$ and serum $17 \beta$-oestradiol $(R=-0.72$; $P=0.002)$

range $88 \pm 24 \mathrm{pmol} / \mathrm{l}$ (14). Bioavailable oestrogen concentration decreases by about $47 \%$ from the age of 25 years to 85 years in men, as a result of the increase in serum SHBG concentrations (9). It is thus noteworthy that the effects of tamoxifen and raloxifene in men occur in individuals with significantly greater serum concentrations of bioavailable $17 \beta$-oestradiol, compared with their use in postmenopausal women, in whom $17 \beta$-oestradiol concentrations are very low. Tamoxifen used in male infertility increases serum concentrations of LH, FSH and testosterone $(36,37)$. Treatment of elderly males with raloxifene $60 \mathrm{mg} /$ day increased only serum FSH significantly, with no effect on serum LH and testosterone (27).

In our study, administration of raloxifene $120 \mathrm{mg} /$ day significantly increased the concentrations of gonadotrophins, so there is probably a dose-dependent effect of raloxifene on gonadotrophin secretion. In adult men, 17ß-oestradiol inhibits LH and FSH secretion (38), and the increase in serum LH and FSH are probably best explained by an antioestrogenic effect of raloxifene on the male pituitary-hypothalamus axis. Probably, serum total testosterone and $17 \beta$-oestradiol concentrations increased secondarily to the increase in serum LH. No relationship was found between baseline serum concentrations of total testosterone and oestrogen and the quantitative increase in both sex hormones during raloxifene treatment. We found a significant relationship between change (increase) in serum LH and the change (increase) in serum testosterone concentrations. The increase in SHBG, produced by the liver (39), can be a direct effect of the increase in serum $17 \beta$-oestradiol concentration or the result of the oestrogen-agonistic effect of raloxifene, occurring in spite of an increase in serum testosterone that decreases SHBG production. The values of both total and free serum testosterone increased by about $20 \%$. It is now well documented that, in the ageing male, serum total testosterone concentrations - and, to an even greater extent, those of free testosterone - decline. Several clinical studies show beneficial effects of testosterone supplementation on bone and muscle mass in ageing men with decreased testosterone concentrations, although study findings have not been unanimously positive (40-44).

In our study, serum total PSA concentrations increased significantly during treatment with raloxifene, but without significant changes in serum free PSA concentrations and the free/total PSA ratio. This is probably the result of the increase in serum testosterone concentrations, as this increase in serum PSA can also be seen during treatment of hypogonadal males with testosterone $(45,46)$. In vitro, raloxifene induces apoptosis in androgen-responsive and androgen-independent human prostate cancer cell lines $(47,48)$. These findings suggest that agents with mixed oestrogen agonist/antagonist effects might be potential targets for therapeutic strategies in patients with prostate cancer.

In addition to androgens, oestrogens have an important role in male bone (patho)physiology. Oestrogens are important for bone mineral density, circulating concentrations having a key role in determining peak bone mass in young men. Bone loss is greater when serum concentrations of bioavailable $17 \beta$-oestradiol are low in elderly men $(9,49,50)$. In addition, bone mineral density was positively associated with greater serum $17 \beta$-oestradiol concentrations in elderly men (51). Age-related decreases in serum bioavailable 17ß-oestradiol, especially concentrations less than $40 \mathrm{pmol} / \mathrm{l}$, may be a major predictor of bone loss in elderly men (for review see (7)). It was therefore of interest to monitor the effects of the administration of raloxifene on surrogate markers of bone metabolism in the men in our study. In the study, we measured total serum alkaline phosphatase and $2 \mathrm{~h}$ fasting urine OHPro/creatinine 
ratio as markers of bone metabolism. Treatment with $120 \mathrm{mg}$ raloxifene for 3 months had no significant effects on any of the markers. A negative correlation was apparent between the increase in serum total oestrogen and testosterone concentrations with raloxifene and the used marker of bone resorption. This reduced bone resorption could be the effect of an increase in total $17 \beta$-oestradiol resulting from increased aromatisation of testosterone; however, it may also have been the result of the increase in serum testosterone itself. The lack of a demonstrable effect of raloxifene on bone markers may have been attributable to our laboratory methods. Urine OHPro is a rather unspecific marker of bone resorption, as it is derived from the degradation of various forms of collagen and also from the diet (28). In postmenopausal women with osteoporosis, the effects of raloxifene have been well studied: it decreases the risk of vertebral fractures, but not of hip fractures, bone mineral density increases in both lumbar spine and hip, and markers for bone turnover decrease by about $40 \%(1,4,23)$. One other study in elderly men also investigated the effects of raloxifene on bone turnover (27). This study found no net effect of raloxifene $60 \mathrm{mg} /$ day on bone resorption in elderly men. However, in a subset of men with low serum total $17 \beta$-oestradiol concentrations, raloxifene seemed to decrease bone resorption (27). We did not find such an effect, but we have not used the more sensitive marker of bone resorption, urine deoxypyridinoline. Thus, in men, raloxifene might exert some effect on bone metabolism only if serum concentrations of $17 \beta$-oestradiol are low.

Administration of raloxifene to postmenopausal women produced modest beneficial effects on surrogate markers of cardiovascular risks. In most studies, administration of raloxifene decreased serum TChol and LDL-c, whereas no effects on serum HDL-c and triglyceride were noted $(2,3,24)$. In our study, a small but significant decrease in serum TChol, with a trend to a decrease in serum concentrations of LDL-c and HDL-c, was noted. No effect was found on serum triglyceride concentrations. The findings of other studies showed a decrease in TChol (22) or no effect (27). This effect may be dose dependent, as we used a greater dose of raloxifene. No serious side effects occurred during treatment with raloxifene, and the increase in serum $17 \beta$-oestradiol did not cause gynaecomastia.

In summary, our study in healthy elderly men showed that raloxifene $120 \mathrm{mg} /$ day for 3 months increased serum LH, FSH and sex steroid hormone concentrations. In addition, a small but significant decrease in serum TChol was found, without an associated effect on serum LDL-c, HDL-c and triglyceride. The significant increase in serum total PSA was probably the result of the increase in serum testosterone; its pathophysiological significance is uncertain, as there is no strong evidence of a relationship between serum concentrations of testosterone and (future) prostate pathology (52). For the entire group, no change in markers of bone resorption was found. Only in the men with a relatively greater increase in serum total testosterone and oestrogen in response to raloxifene administration was a decrease in the markers of bone resorption found. This seems to be comparable to the findings of others who treated men older than 65 years with testosterone (41). Only those men with low serum testosterone concentrations before treatment exhibited an increase in lumbar spine bone density.

In conclusion, we have failed to prove our hypothesis that increasing plasma testosterone by means of the mixed oestrogen agonist/antagonist, raloxifene, might have beneficial effects on androgen- and oestrogendependent organs/systems. Beneficial effects, if any, were of marginal magnitude, and we found no indications for the administration of raloxifene to ageing men.

\section{Acknowledgements}

We are grateful to Ms Ans Nicolaas-Merkus and the endocrine laboratory for their excellent assistance in the execution of the study.

\section{References}

1 Delmas PD, Ensrud KE, Adachi JD, Harper KD, Sarkar S, Gennari C et al. Efficacy of raloxifene on vertebral fracture risk reduction in postmenopausal women with osteoporosis: four-year results from a randomized clinical trial. Journal of Clinical Endocrinology and Metabolism 200287 3609-3617.

2 Delmas PD, Bjarnason NH, Mitlak BH, Ravoux AC, Shah AS, Huster WJ et al. Effects of raloxifene on bone mineral density, serum cholesterol concentrations, and uterine endometrium in postmenopausal women. New England Journal of Medicine 1997 $3371641-1647$.

3 Walsh BW, Paul S, Wild RA, Dean RA, Tracy RP, Cox DA et al. The effects of hormone replacement therapy and raloxifene on C-reactive protein and homocysteine in healthy postmenopausal women: a randomized, controlled trial. Journal of Clinical Endocrinology and Metabolism 200085 214-218.

4 Ettinger B, Black DM, Mitlak BH, Knickerbocker RK, Nickelsen T, Genant HK et al. Reduction of vertebral fracture risk in postmenopausal women with osteoporosis treated with raloxifene: results from a 3-year randomized clinical trial. Multiple Outcomes of Raloxifene Evaluation (MORE) Investigators. Journal of the American Medical Association $1999282637-645$.

5 Tenover JL. Male hormone replacement therapy including 'andropause'. Endocrinology and Metabolism Clinics of North America 199827 969-987.

6 Harman SM, Metter EJ, Tobin JD, Pearson J \& Blackman MR. Longitudinal effects of aging on serum total and free testosterone levels in healthy men. Baltimore Longitudinal Study of Aging. Journal of Clinical Endocrinology and Metabolism $2001 \mathbf{8 6}$ 724-731.

7 Khosla S, Melton LJ, III \& Riggs BL. Clinical review 144: estrogen and the male skeleton. Journal of Clinical Endocrinology and Metabolism 200287 1443-1450.

8 Faustini-Fustini M, Rochira V \& Carani C. Oestrogen deficiency in men: where are we today? European Journal of Endocrinology 1999 $140111-129$. 
9 Khosla S, Melton LJ III, Atkinson EJ, O’Fallon WM, Klee GG \& Riggs BL. Relationship of serum sex steroid levels and bone turnover markers with bone mineral density in men and women: a key role for bioavailable estrogen. Journal of Clinical Endocrinology and Metabolism $1998 \mathbf{8 3} 2266-2274$.

10 Resnick SM \& Maki PM. Effects of hormone replacement therapy on cognitive and brain aging. Annals of the New York Academy of Sciences $2001949203-214$.

11 Komesaroff PA, Fullerton M, Esler MD, Dart A, Jennings G \& Sudhir K. Low-dose estrogen supplementation improves vascular function in hypogonadal men. Hypertension $2001 \mathbf{3 8}$ 1011-1016.

12 Sader MA, McCredie RJ, Griffiths KA, Wishart SM, Handelsman DJ \& Celermajer DS. Oestradiol improves arterial endothelial function in healthy men receiving testosterone. Clinical Endocrinology 2001 54 $175-181$.

13 Sudhir K \& Komesaroff PA. Clinical review 110: cardiovascular actions of estrogens in men. Journal of Clinical Endocrinology and Metabolism 199984 3411-3415.

14 Gooren LJ \& Toorians AW. Significance of oestrogens in male (patho)physiology. Annals of Endocrinology (Paris) $20036 \mathbf{6 4}$ 126-135.

15 Carani C, Rochira V, Faustini-Fustini M, Balestrieri A \& Granata AR. Role of oestrogen in male sexual behaviour: insights from the natural model of aromatase deficiency. Clinical Endocrinology $199951517-524$.

16 Yeh S, Miyamoto H, Shima H \& Chang C. From estrogen to androgen receptor: a new pathway for sex hormones in prostate. Proceedings of the National Academy of Sciences of the United States of America 199895 5527-5532.

17 Jordan VC. Tamoxifen: a most unlikely pioneering medicine. Nature Reviews Drug Discovery 20032 205-213.

18 Sayer HG, Kath R, Kliche KO \& Hoffken K. Premenopausal breast cancer: chemotherapy and endocrine therapy. Drugs 200262 2025-2038.

19 McDonald CC \& Stewart HJ. Fatal myocardial infarction in the Scottish adjuvant tamoxifen trial. The Scottish Breast Cancer Committee. British Medical Journal 1991303 435-437.

20 McDonald CC, Alexander FE, Whyte BW, Forrest AP \& Stewart HJ. Cardiac and vascular morbidity in women receiving adjuvant tamoxifen for breast cancer in a randomised trial. The Scottish Cancer Trials Breast Group. British Medical Journal 1995311 977-980.

21 Clarke SC, Schofield PM, Grace AA, Metcalfe JC \& Kirschenlohr HL. Tamoxifen effects on endothelial function and cardiovascular risk factors in men with advanced atherosclerosis. Circulation 2001 103 1497-1502.

22 Blum A, Hathaway L, Mincemoyer R, Schenke WH, Csako G, Waclawiw MA et al. Hormonal, lipoprotein, and vascular effects of the selective estrogen receptor modulator raloxifene in hypercholesterolemic men. American Journal of Cardiology 2000 $851491-1494$.

23 Meunier PJ, Vignot E, Garnero P, Confavreux E, Paris E, Lui-Leage $\mathrm{S}$ et al. Treatment of postmenopausal women with osteoporosis or low bone density with raloxifene. Raloxifene Study Group. Osteoporosis International $199910330-336$.

24 de Valk-de Roo GW, Stehouwer CD, Meijer P, Mijatovic V, Kluft C, Kenemans $\mathrm{P}$ et al. Both raloxifene and estrogen reduce major cardiovascular risk factors in healthy postmenopausal women: a 2-year, placebo-controlled study. Arteriosclerosis, Thrombosis and Vascular Biology 199919 2993-3000.

25 Mijatovic V, van der Mooren MJ, Kenemans P, de Valk-de Roo GW \& Netelenbos C. Raloxifene lowers serum lipoprotein(A) in healthy postmenopausal women: a randomized, double-blind, placebo-controlled comparison with conjugated equine estrogens. Menopause $19996134-137$.

26 Walsh BW, Kuller LH, Wild RA, Paul S, Farmer M, Lawrence JB et al. Effects of raloxifene on serum lipids and coagulation factors in healthy postmenopausal women. Journal of the American Medical Association 1998279 1445-1451.
27 Doran PM, Riggs BL, Atkinson EJ \& Khosla S. Effects of raloxifene, a selective estrogen receptor modulator, on bone turnover markers and serum sex steroid and lipid levels in elderly men. Journal of Bone and Mineral Research 200116 2118-2125.

28 Russell RG. The assessment of bone metabolism in vivo using biochemical approaches. Hormone and Metabolic Research 199729 138-144.

29 Teerlink T, Tavenier P \& Netelenbos JC. Selective determination of hydroxyproline in urine by high-performance liquid chromatography using precolumn derivatization. Clinica Chimica Acta 1989183 309-315.

30 Vermeulen A, Verdonck L \& Kaufman JM. A critical evaluation of simple methods for the estimation of free testosterone in serum. Journal of Clinical Endocrinology and Metabolism $1999 \mathbf{8 4}$ 3666-3672.

31 Cauley JA, Norton L, Lippman ME, Eckert S, Krueger KA, Purdie DW et al. Continued breast cancer risk reduction in postmenopausal women treated with raloxifene: 4-year results from the MORE trial. Multiple outcomes of raloxifene evaluation. Breast Cancer Research and Treatment 2001 65 125-134.

32 Cummings SR, Eckert S, Krueger KA, Grady D, Powles TJ, Cauley JA et al. The effect of raloxifene on risk of breast cancer in postmenopausal women: results from the MORE randomized trial. Multiple Outcomes of Raloxifene Evaluation. Journal of the American Medical Association 1999281 2189-2197.

33 Davies GC, Huster WJ, Shen W, Mitlak B, Plouffe L Jr, Shah A et al. Endometrial response to raloxifene compared with placebo, cyclical hormone replacement therapy, and unopposed estrogen in postmenopausal women. Menopause 19996 188-195.

34 Plouffe L Jr \& Siddhanti S. The effect of selective estrogen receptor modulators on parameters of the hypothalamic-pituitary-gonadal axis. Annals of the New York Academy of Sciences 2001949 251-258.

35 Reindollar R, Koltun W, Parsons A, Rosen A, Siddhanti S \& Plouffe L Jr. Effects of oral raloxifene on serum estradiol levels and other markers of estrogenicity. Fertility and Sterility 2002 78 469-472.

36 Kadioglu TC, Koksal IT, Tunc M, Nane I \& Tellaloglu S. Treatment of idiopathic and postvaricocelectomy oligozoospermia with oral tamoxifen citrate. British Journal of Urology International 1999 $83646-648$.

37 Vandekerckhove P, Lilford R, Vail A \& Hughes E. Clomiphene or tamoxifen for idiopathic oligo/asthenospermia. Cochrane Database of Systematic Reviews 20002 CD000151.

38 Hayes FJ, Seminara SB, DeCruz S, Boepple PA \& Crowley WF Jr. Aromatase inhibition in the human male reveals a hypothalamic site of estrogen feedback. Journal of Clinical Endocrinology and Metabolism $2000853027-3035$.

39 Kahn SM, Hryb DJ, Nakhla AM, Romas NA \& Rosner W. Sex hormone-binding globulin is synthesized in target cells. Journal of Endocrinology $2002175113-120$.

40 Vermeulen A. Andropause. Maturitas 2000 34 5-15.

41 Snyder PJ, Peachey H, Hannoush P, Berlin JA, Loh L, Holmes JH et al. Effect of testosterone treatment on bone mineral density in men over 65 years of age. Journal of Clinical Endocrinology and Metabolism 199984 1966-1972.

42 Urban RJ, Bodenburg YH, Gilkison C, Foxworth J, Coggan AR, Wolfe RR et al. Testosterone administration to elderly men increases skeletal muscle strength and protein synthesis. American Journal of Physiology 1995269 E820-E826.

43 Sih R, Morley JE, Kaiser FE, Perry HM, III, Patrick P \& Ross C. Testosterone replacement in older hypogonadal men: a 12-month randomized controlled trial. Journal of Clinical Endocrinology and Metabolism 199782 1661-1667.

44 Hajjar RR, Kaiser FE \& Morley JE. Outcomes of long-term testosterone replacement in older hypogonadal males: a retrospective analysis. Journal of Clinical Endocrinology and Metabolism 1997 $823793-3796$. 
45 Guay AT, Perez JB, Fitaihi WA \& Vereb M. Testosterone treatment in hypogonadal men: prostate-specific antigen level and risk of prostate cancer. Endocrine Practice 20006 132-138.

46 Gerstenbluth RE, Maniam PN, Corty EW \& Seftel AD. Prostatespecific antigen changes in hypogonadal men treated with testosterone replacement. Journal of Andrology $2002 \quad 23$ 922-926.

47 Kim IY, Seong DH, Kim BC, Lee DK, Remaley AT, Leach F et al. Raloxifene, a selective estrogen receptor modulator, induces apoptosis in androgen-responsive human prostate cancer cell line LNCaP through an androgen-independent pathway. Cancer Research $2002623649-3653$.

48 Kim IY, Kim BC, Seong DH, Lee DK, Seo JM, Hong YJ et al. Raloxifene, a mixed estrogen agonist/antagonist, induces apoptosis in androgen-independent human prostate cancer cell lines. Cancer Research $2002625365-5369$.

49 Khosla S, Melton LJ III, Atkinson EJ \& O'Fallon WM. Relationship of serum sex steroid levels to longitudinal changes in bone density in young versus elderly men. Journal of Clinical Endocrinology and Metabolism 200186 3555-3561.

50 Greendale GA, Edelstein S \& Barrett-Connor E. Endogenous sex steroids and bone mineral density in older women and men: the Rancho Bernardo Study. Journal of Bone and Mineral Research 199712 1833-1843.

51 Slemenda CW, Longcope C, Zhou L, Hui SL, Peacock M \& Johnston CC. Sex steroids and bone mass in older men. Positive associations with serum estrogens and negative associations with androgens. Journal of Clinical Investigation $1997 \mathbf{1 0 0}$ 1755-1759.

52 Morales A. Androgen replacement therapy and prostate safety. European Urology $2002 \mathbf{4 1} 113-120$.

Received 10 September 2003

Accepted 9 January 2004 